\title{
System-Level Testing of the Advanced Stirling Radioisotope Generator Engineering Hardware
}

\author{
Jack Chan ${ }^{1}$ \\ Lockheed Martin Space Systems Company, King of Prussia, Pennsylvania 19406 \\ Joel Wiser ${ }^{2}$, Greg Brown ${ }^{3}$ \\ Lockheed Martin Space Systems Company, Louisville, CO 80027 \\ Dominic Florin ${ }^{4}$ \\ Lockheed Martin Space Systems Company, Louisville, CO 80027 \\ and \\ Salvatore M. Oriti ${ }^{5}$ \\ NASA Glenn Research Center, Cleveland, OH 44135
}

\begin{abstract}
To support future NASA deep space missions, a radioisotope power system utilizing Stirling power conversion technology was under development. This development effort was performed under the joint sponsorship of the Department of Energy and NASA, until its termination at the end of 2013 due to budget constraints. The higher conversion efficiency of the Stirling cycle compared with that of the Radioisotope Thermoelectric Generators (RTGs) used in previous missions (Viking, Pioneer, Voyager, Galileo, Ulysses, Cassini, Pluto New Horizons and Mars Science Laboratory) offers the advantage of a four-fold reduction in ${ }^{238} \mathrm{Pu}$ fuel, thereby extending its limited domestic supply. As part of closeout activities, system-level testing of flight-like Advanced Stirling Convertors (ASCs) with a flight-like ASC Controller Unit (ACU) was performed in February 2014. This hardware is the most representative of the flight design tested to date. The test fully demonstrates the following ACU and system functionality: system startup; ASC control and operation at nominal and worst-case operating conditions; power rectification; DC output power management throughout nominal and out-of-range host voltage levels; ACU fault management, and system command / telemetry via MIL-STD 1553 bus. This testing shows the viability of such a system for future deep space missions and bolsters confidence in the maturity of the flight design.
\end{abstract}

$\begin{array}{ll} & \\ \text { ACU } & =\text { Advanced Stirling Convertor Controller Unit } \\ \text { ASC } & =\text { Advanced Stirling Convertor } \\ \text { ASRG } & =\text { Advanced Stirling Radioisotope Generator } \\ \text { BOM } & =\text { Beginning of Mission } \\ \text { EDU } & =\text { Engineering Development Unit } \\ \text { EU } & =\text { Engineering Unit } \\ \text { GHA } & =\text { Generator Housing Assembly } \\ \text { MOSFET } & =\text { Metal-Oxide Semiconductor Field-Effect Transistor }\end{array}$

\footnotetext{
${ }^{1}$ Principal Systems Engineer, Energy Systems, 230 Mall Boulevard, B100/M2307.

2 Senior Electronics Engineer, Coherent Technologies, 135 S. Taylor Avenue, CTS/FL2.

${ }^{3}$ Staff Systems Engineer, Coherent Technologies, 135 S. Taylor Avenue, CTS/FL2.

${ }^{4}$ Staff S/W Engineer, Coherent Technologies, 135 S. Taylor Avenue, CTS/FL2.

${ }^{5}$ Mechanical Engineer, Thermal Energy Conversion Branch, 21000 Brookpark Rd.
} 


\section{Introduction}

$\mathrm{T}$ he Advanced Stirling Radioisotope Generator (ASRG) was under development from 2006 to 2013 with the objective of providing a high-efficiency, low-mass radioisotope power system for future NASA missions. Lockheed Martin Space Systems Company served as the system integrator under contract to DOE. Sunpower, Inc. of Athens, OH developed the Advanced Stirling Convertor (ASC) for use with the ASRG, and NASA Glenn Research Center (GRC) provided the R\&D and test support for the engineering ASCs, denoted as ASC-Es. Utilizing Stirling cycle power conversion, the ASRG provides a four-fold reduction in radioisotope fuel per watt generated over the traditional thermoelectric convertors.

An electrically heated Engineering Unit (EU) ASRG was assembled and tested to qualification level in $2008^{1}$. The EU has the first generation of ASCs with Inconel heater head for lower hot-end temperature capability than the flight ASCs; and the ASC Controller Unit (ACU), denoted as Engineering Development Unit 1 (EDU 1), was the first design that incorporated the necessary features and functionalities required for space missions. Upon completion of the test, the EU was shipped to NASA GRC for extended operation and accumulated over 33,000 hours of total runtime ${ }^{2}$.

The ASRG completed the final design review in 2012 and was offered as a candidate power supply for NASA Discovery 12 mission, but the proposed missions enabled by the use of ASRG were not down-selected. Lacking a first-mission opportunity combined with the funding constraint and the projection that the U.S. domestic plutonium238 production restart could meet the need of future planetary requirements, the ASRG project was terminated in November 2013. At the time of project termination, the ASRG was in the process of fabricating the Qualification Unit hardware. Parallel to the fabrication activity, flight-like ASC-E3s and ACU EDU 4 were built and tested separately to verify their design compliances and functionalities. As part of the flight project closeout activities, a system-level characterization test of a pair of ASC-E3s and EDU 4 in the Open Frame Assembly (OFA) configuration was conducted to demonstrate the performance and interactions between the ASCs and ACU and the ACU interfaces to the host spacecraft bus. This paper provides a brief description of flight ASRG, the test articles configuration, tests conducted and the results.

\section{Flight ASRG Design}

The ASRG, depicted in Figure 1, consists of four major components: General Purpose Heat Source (GPHS), ASC, Generator Housing Assembly (GHA), and ACU. With the exception of the ACU and associated harnesses, the GHA provides the main support structure and thermal path for the balance of the ASRG hardware. A pair of ASCs is mounted in opposing direction inside the GHA with heat input from its dedicated GPHS. This configuration facilitates fueling with the GPHS while ensuring good thermal contact between the ASC and GPHS, and prevents thermal propagation to the entire GHA in the event of an ASC failure. A thermal insulation assembly encloses the GPHS to maximize thermal efficiency. The heat source support provides the preload to the GPHS to sustain exposure to dynamic environments during launch and planetary entry and surface landing. Internal GHA gas management is provided by the gas management valve and the pressure release device for ground and space flight

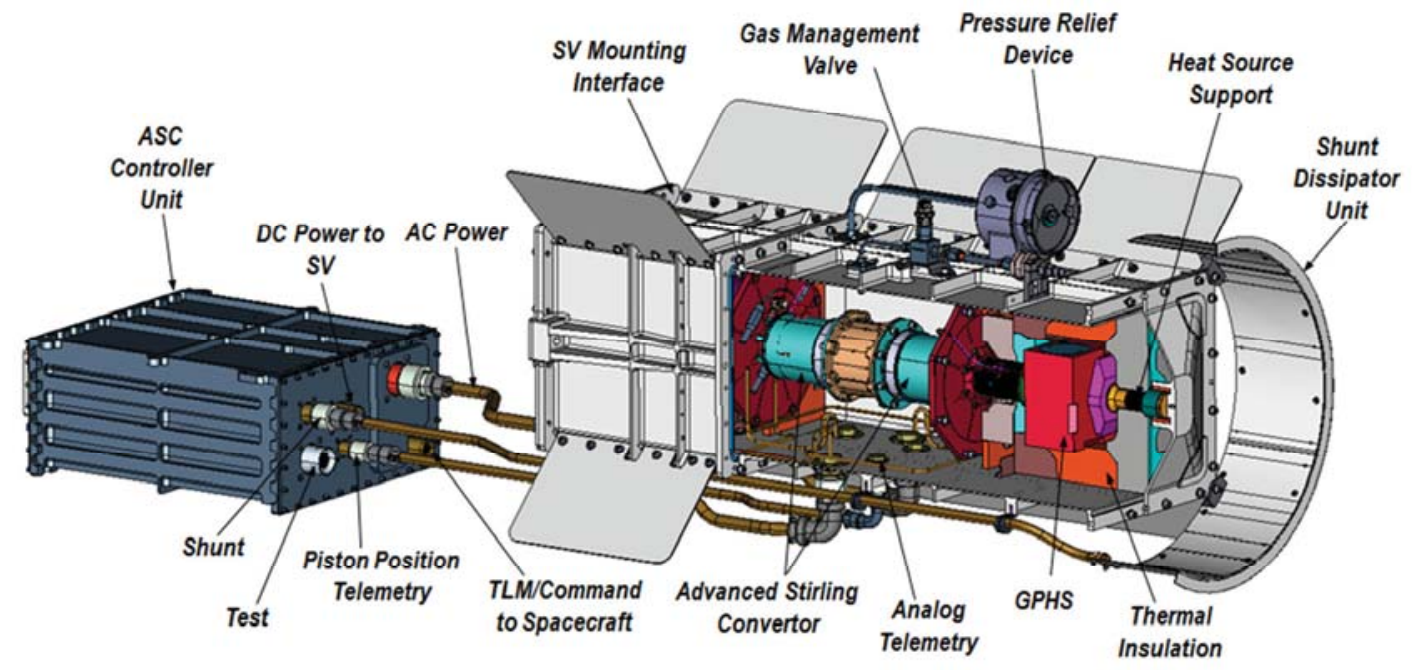

Figure 1. Advanced Stirling Radioisotope Generator cutaway view. 
operations, respectively. An external shunt dissipater unit is mounted at the GHA outboard end to dissipate excess electrical power when the host spacecraft is out of nominal bus voltage range. The GHA is designed to be cantilever mounted to the host spacecraft in any orientation.

The ACU is an active power factor design, synchronizing the ASCs and maintaining a fixed-frequency operating point. It uses high-frequency pulse-width modulation to create a sinusoidal voltage waveform to control the piston motion. The ACU is single-fault tolerant with an $\mathrm{N}+1$ redundancy. It serves as the ASRG electrical interface to the host spacecraft, supplies converted DC power at the host bus voltage, provides ASC and ACU health status via MIL-STD-1553 telemetry, and responds to host commands for operational changes. The ASC health status is monitored directly by the host spacecraft via temperature sensors at the ASC hot and cold heat exchangers and at the alternator. A senor in the ASC detects the location of the piston during each thermodynamic cycle and is signal processed by the ACU as telemetry. The ASRG operates autonomously, with operational commands from the host spacecraft needed only to optimize output power due to radioisotope fuel decay or severe changes to mission environment.

\section{System-Level Engineering Test Configuration}

The first pair of ASC-E3s, serial numbers 1 and 2 (E3 \#1 and \#2), were fabricated by Sunpower and delivered to GRC in November 2012 for extended operation. These convertors have each accumulated over 3,000 hours of operation with their performance fully characterized. To prepare for the system-level performance testing with the ACU EDU 4, the ASC-E3 \#1 and \#2 were assembled in a dual-opposed, flight-like configuration at NASA GRC. Electrical connectors for interface with the ACU, mimicking those of the flight design in the ground test configuration prior to fueling, were installed. Figure 2 shows the configuration of the ASC test article with electrical / mechanical connection panel. The ASC waste heat is actively controlled with cooling loops at the ASC cold heat exchanger and alternator to simulate the typical temperature gradients that would be experienced in the ASRG during mission.

The ACU EDU 4 was configured in an Open Frame Assembly (OFA), shown in Figure 3, to facilitate card-level testing in its build process. The ACU consists of three controller cards; two are active and one on warm standby to take over control of an ASC in the event of a card failure. Daughter boards consisting of circuitries to drive and process piston sensor signals are mounted on two cards. A solid state relay board for switching the ASCs to the appropriate control cards and a backplane form the remainders of the printed circuit boards in the ACU.

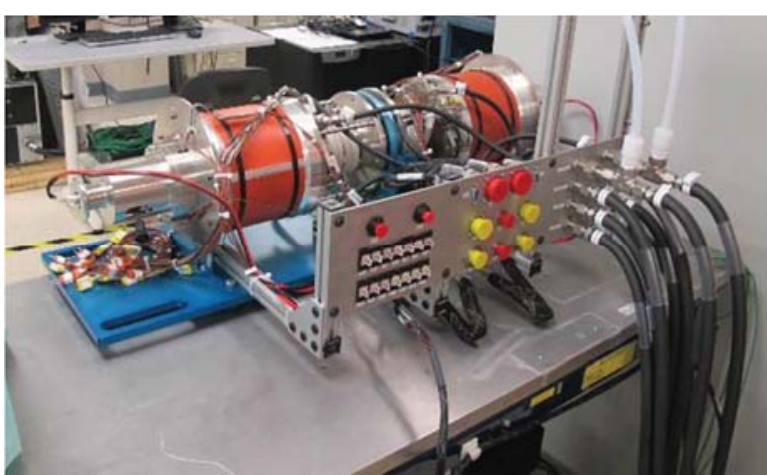

Figure 2. ASC-E3 \#1 and \#2 Test Article Configuration.

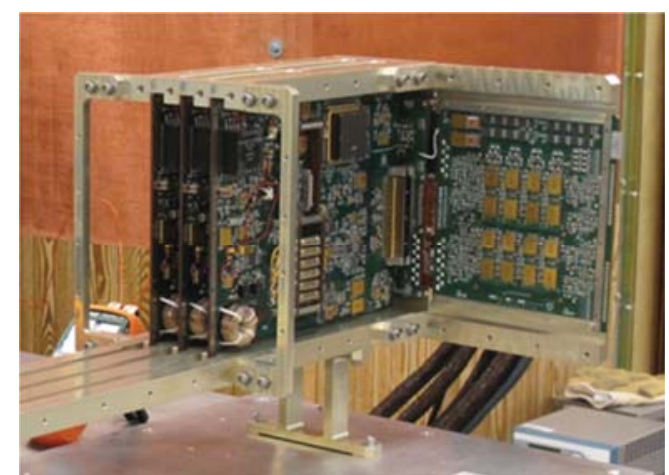

Figure 3. ACU EDU 4 Open Frame Assembly.

The ASC-E3s and EDU 4 OFA test was conducted using the electrical ground support equipment fabricated for qualification / flight ACU and system testing at various ground processing stages. Graphical user interface is utilized to provide input / output interfaces to the ACU for command, telemetry and operational status. Figure 4 shows the configuration of the test setup.

\section{Test Cases}

For deep space missions, thermal modeling of the ASRG has determined that the ASCs will operate at a coldside heat exchanger temperature of about $38^{\circ} \mathrm{C}$ at $760^{\circ} \mathrm{C}$ hot-end temperature. This represents the typical ASC operating condition with the ASRG in $4 \mathrm{~K}$ environment and at the maximum power output at beginning of mission (BOM). At the other extreme, the ASRG has to survive maximum qualification (Max Qual) temperature condition to verify its margins on the design and manufacturing. The qualification temperature is limited by the permanent magnet in the ASC, and for ASRG the limit is about $130^{\circ} \mathrm{C}$. At this temperature, the ASC voltage will be at its 


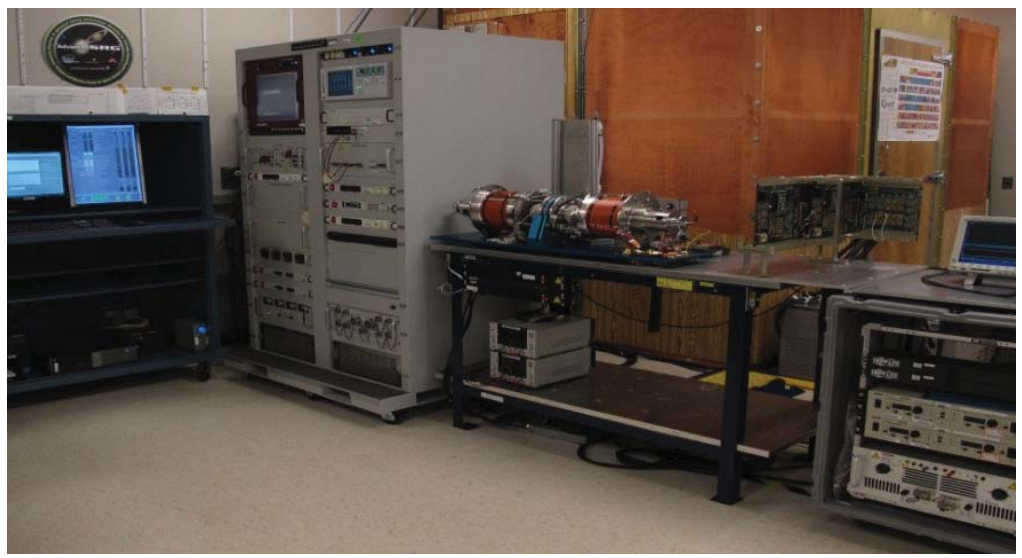

Figure 4. ACU / ASC Test Setup.

ASCs under various system operating conditions. Some of these include:

- Host bus capacitance variation

- Host bus recovery assist

- Host bus voltage variation

- ASC commanded voltage change and phase offset

- ASC dynamic disturbances

- ASC capacitance variation

- AC power fault threshold and card failover

These parameters were varied during the test to characterize the interactions between the ACU and the ASCs and the potential effects on ASC operation and host bus interface.

Prior to the test, extensive calibration of the piston sensor signals for piston position and amplitude using the ACU daughter board was performed. The data were compared to those established during ASC buildup and testing at Sunpower and it was concluded that these measurements are repeatable from one test site to another, providing confidence that the ASCs can be safely controlled and monitored during operation.

\section{Test Results}

\section{A. Power Output}

As part of piston sensor dynamic calibration test, the ASC piston amplitude was varied from 3.0 to $4.5 \mathrm{~mm}$ via voltage commands from the ACU while operating under the BOM condition. The electric heater power supplied to the ASCs was controlled in a constant hot-end temperature mode so that the temperature effects due to large piston amplitude changes during the test are minimized. This test produced a wide range of power output conditions beyond that expected from a typical space mission. Figure 5 shows the profiles of ASC power output, power to the host DC bus, and the calculated ACU power loss for three ASC cold-side temperature and four piston amplitude cases. As the piston amplitude increases, more heat is converted to mechanical energy and then to AC power. As the cold-side temperature increases, the Stirling cycle becomes less efficient and less power is produced for the same piston amplitude operation, as can be seen after the 200-minute time in Figure 5. The ACU power consumption during this test varied between about 19 and $22.5 \mathrm{~W}$, with higher consumption associated with higher input AC power and corresponding $\mathrm{I}^{2} \mathrm{R}$ loss.

\section{B. Host Bus Voltage Variation}

All power generated by the ASRG is delivered to the host DC bus while in the voltage range of 22 to $34 \mathrm{~V}$. Above $34 \mathrm{~V}$, all the produced power is shunted to the external shunt dissipater shown in Figure 1. Below $22 \mathrm{~V}$, the ACU operates in a bus recovery mode by supplying a constant pulse-width-modulated current to assist the host bus in recovering from a fault. A bus voltage variation test was conducted to demonstrate the interactions between the host bus and the ASRG. After the ASCs reached a steady operating condition in a constant heat input mode, the host bus voltage was adjusted from $28 \mathrm{~V}$ in $1-\mathrm{V}$ increments. The power flow to the host bus with varying host voltages is shown in Figure 6. As the host bus voltage drops below $22 \mathrm{~V}$, a constant 4.5-A current is provided to the bus and the remaining power produced is shunted; beyond $34 \mathrm{~V}$, no power is sourced to the bus and all power produced is shunted. To prevent nuisance oscillations at these transition regions, a hysteresis band is incorporated in the ACU as illustrated by the vertical up / down arrows shown in the figure. The host bus voltage increment was reduced to $0.1-\mathrm{V}$ steps around the over- and under-voltage regions to measure the exact voltages when power is

$$
4
$$

American Institute of Aeronautics and Astronautics 
transitioned. The over-voltage hysteresis was measured to be about $0.7 \mathrm{~V}$ while the under-voltage hysteresis is about $1.5 \mathrm{~V}$.

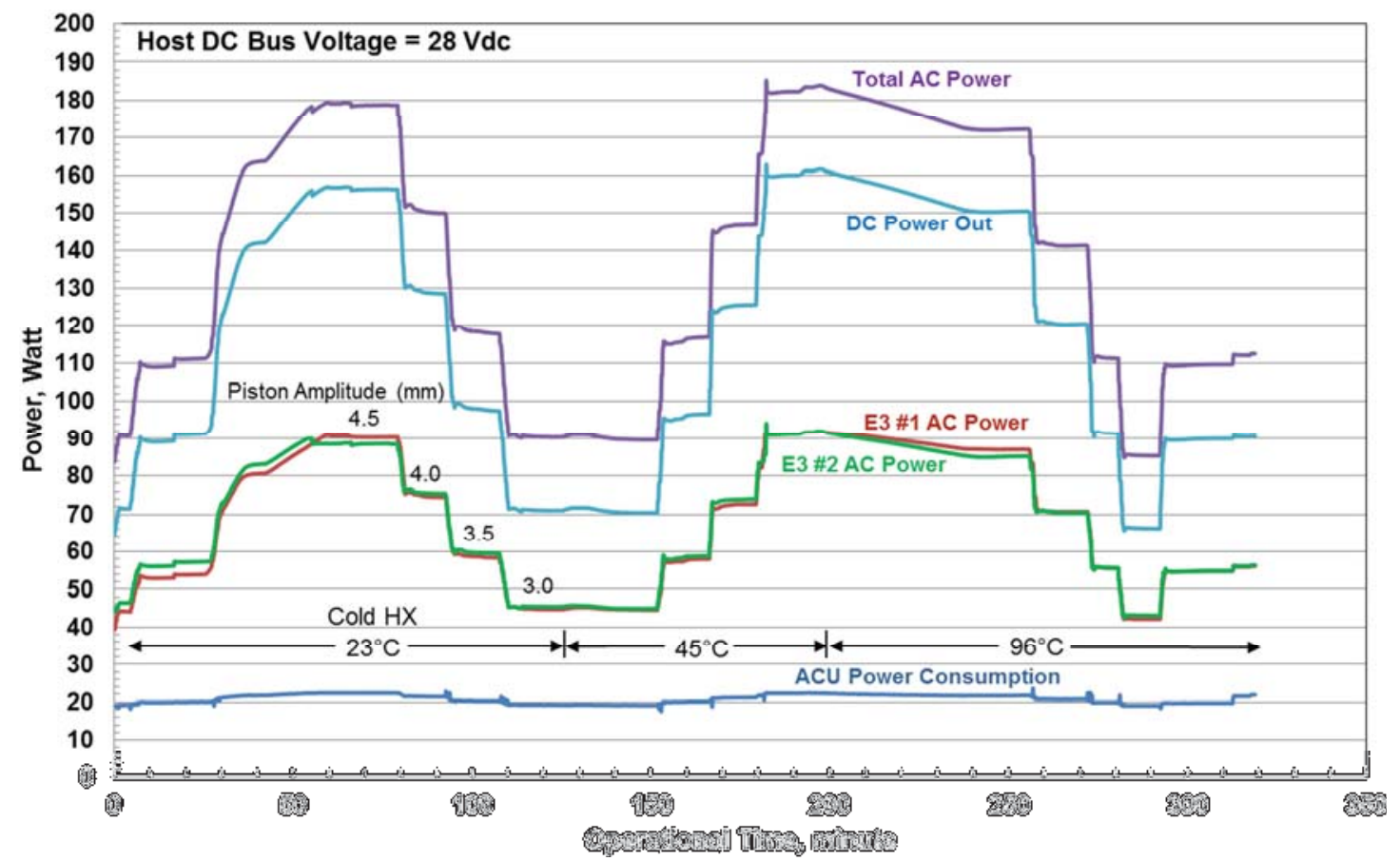

Figure 5. ASC and ACU Power Output Characteristics at 28 Vdc Host Bus.

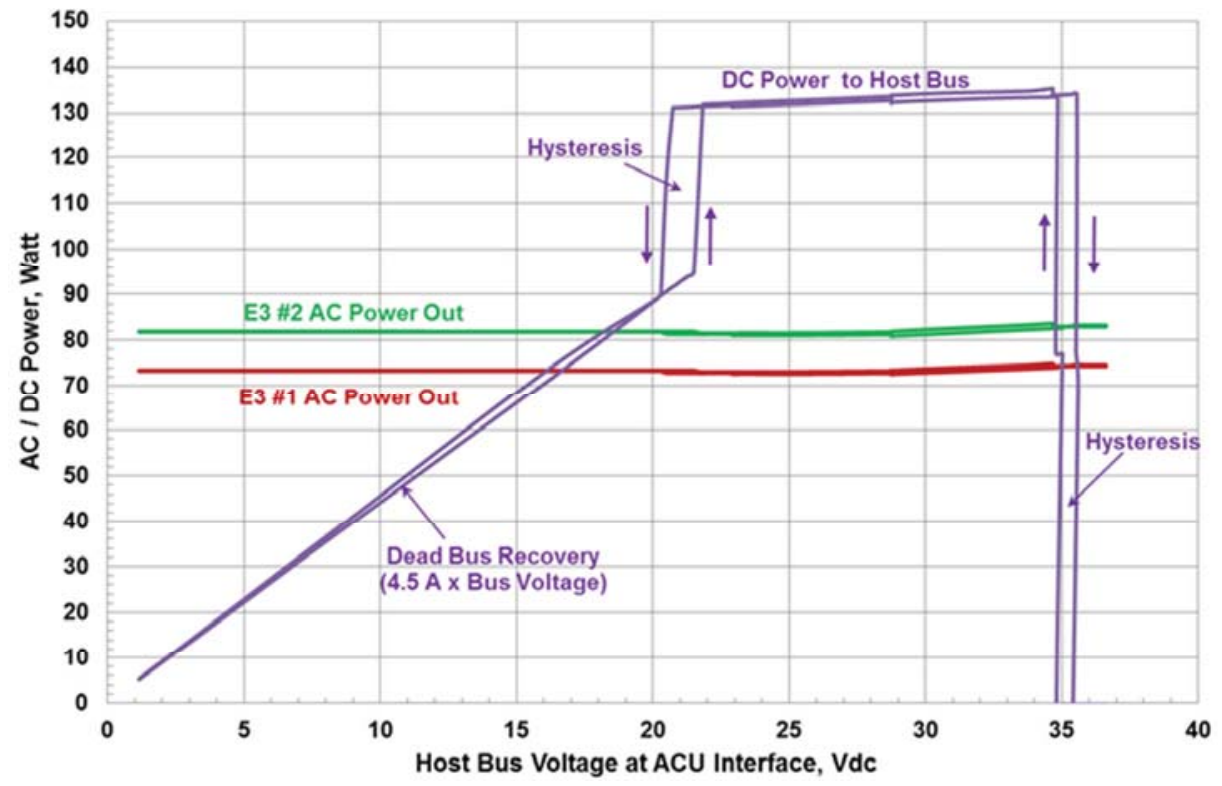

The host bus voltage variation test was conducted over a 5-hour period to observe if it has any effect on the ASC operation. Figure 7 shows the ASC operating characteristics in voltage, piston amplitude and temperatures as the host bus voltage was adjusted over the range of 0.5 to $36 \mathrm{~V}$. As the bus voltage increased from 28 to $36 \mathrm{~V}$, the ASC voltage and piston amplitude increase slightly due to a change to the ACU internal bus voltage set point needed to provide an adequate

Figure 6. ASRG Power Supply as a Function of Host Bus Voltage.

margin for power processing and fault management. This internal bus voltage change affects the H-bridge duty cycle that is required to maintain the ASC at the same commanded voltage. However, the internal bus voltage measurement errors due to DC offset and gain cause the duty cycle adjustment to not exactly match the actual change in the internal bus voltage. The control approach does not actively compare and verify the actual ASC voltage sent to fine tune the H-bridge duty cycle. This results in a small voltage rise and consequently a drop in the 
ASC operating temperature as shown in the figure. This gradual decrease in ASC hot-end temperature causes the ASC voltage to recover somewhat with time as it settles to a new operating state.

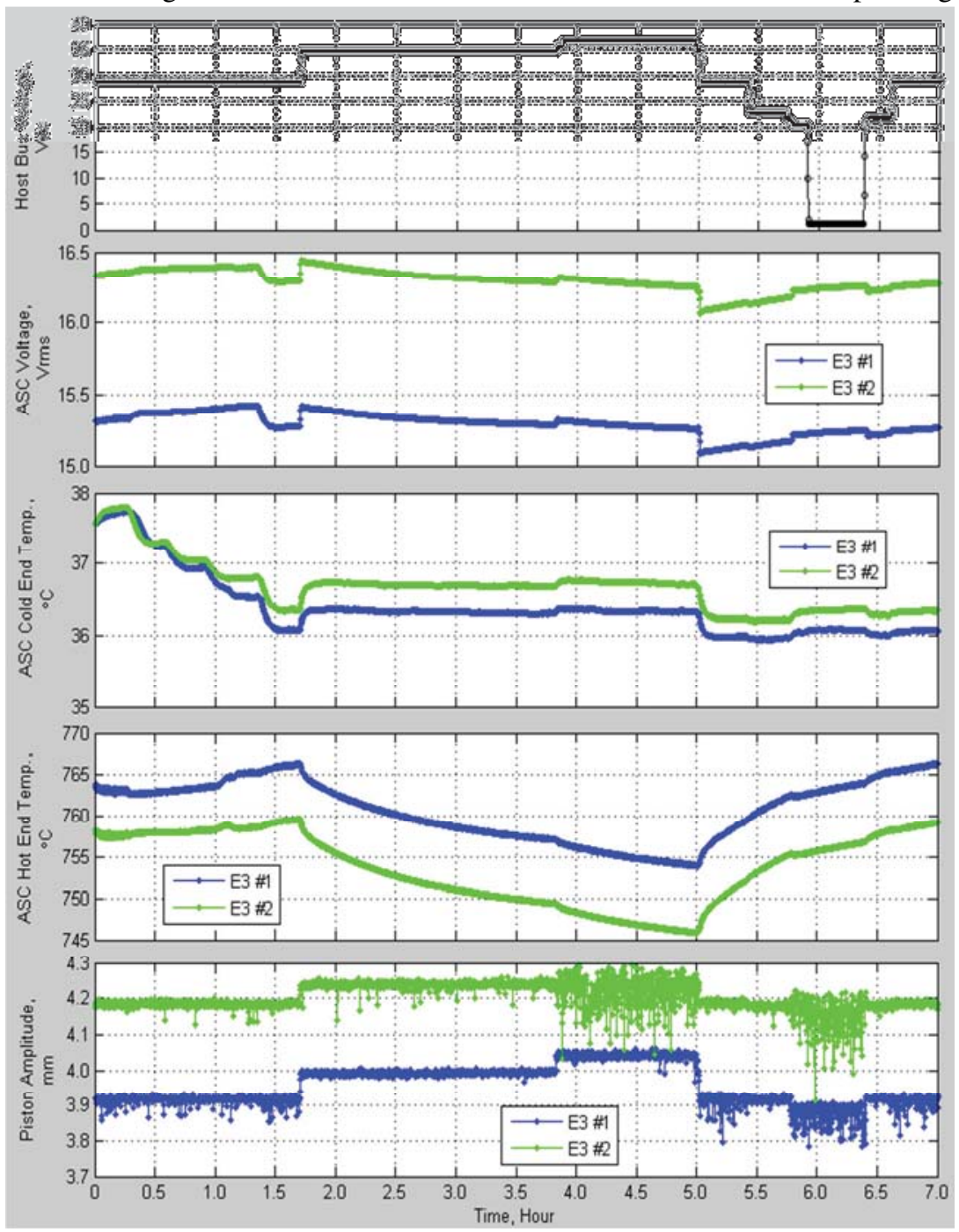

Figure 7. ASC Operation under Host Bus Voltage Variation.

As the host bus voltage increases from 34 to $36 \mathrm{~V}$, the shunt is enabled. The $40-\mathrm{kHz}$ shunting causes a lowamplitude, $40-\mathrm{kHz}$ voltage ripple. The H-bridge duty cycle for ASC alternator voltage is synchronous to the shunt ripple, and as a result, causes a very slight increase in the operating voltage.

As the hot bus returns to nominal and decreasing voltages, the voltage / amplitude trend and temperature effects are reversed. The total change in piston amplitude between 22- and $34-\mathrm{V}$ nominal host bus voltage was approximately $0.08 \mathrm{~mm}$ and $0.05 \mathrm{~mm}$ for E3 \#1 and \#2, respectively. This causes a hot-end temperature change between 20 to $30^{\circ} \mathrm{C}$. From a system operational standpoint, the variation in the host bus voltage will not have an impact on the safe operation of ASC or overall power output, even if an adjustment to the operating voltage is not made.

For future improvement, the alternator voltage, either the actual operating value or the commanded value, could be measured directly and compared / adjusted to the intended set point. This allows a closed loop control and insulates the ASC from any changes or measurement errors in the bus voltage resulting from internal or external effects.

\section{Dynamic Disturbance}

The motions of an ASC piston and displacer in nominal operation generate a cyclical force of around $270 \mathrm{~N}$. With the ASCs mounted in dual-opposing direction inside the GHA, the majority of this force is cancelled out. With each ASC controlled by a dedicated card, the remaining net force can further be reduced, if required by the host spacecraft, via 1553 command with small ASC voltage adjustments. To characterize the dynamic characteristics of the ASC pair in operation, the E3 \#1 and \#2 test article was equipped with a three-axis accelerometer located at the alternator housings mounting flange and the entire test article rested on the bench via four rubber isolators.

Small voltage and voltage phase angle increments were sequentially commanded to one ASC and the accelerometer readings were recorded and converted to forces generated, given the mass of the test article. The force generated by the moving piston and displacer can also be estimated using the ASC build data and piston amplitude measured during test. Figure 8 shows the comparison of the test article force calculated from accelerometer readings to that calculated from ASC build data and piston amplitude measurements. As expected, forces calculated from the accelerometer readings are less than those using the piston and displacer motion data as the former did not include the masses of cooling loops and harnesses that were added later on during test setup integration. Also not included are factors such as damping from the isolators, measurement uncertainties, etc.

To compare the disturbances from the test article setup to that expected in the flight ASRG, a similar correlation was made with the ASRG EU test data taken at NASA GRC. The disturbance force generated was measured with the load cells at the four mounting interface locations at the ASRG. Over 20,750 force data points were collected 
between August 2010 and March 2013. Figure 9 shows the comparison between the load cell measurements and the calculations based on the ASCs build data and measured piston amplitudes. For a rigidly mounted EU to a stiff support structure as in the GRC test configuration, the figure shows that there is a good correlation between the load cell measurements and the calculated force generated by the piston and displacer assemblies, and is consistent with that shown in Figure 8. No attempt was made during this operating period to intentionally reduce the disturbances to a minimum value.

Approximately three-quarter of the force produced comes from the piston, where its amplitude is adjustable via ACU voltage command. With the capability for a very small voltage command step for each ASC in the ASRG, the

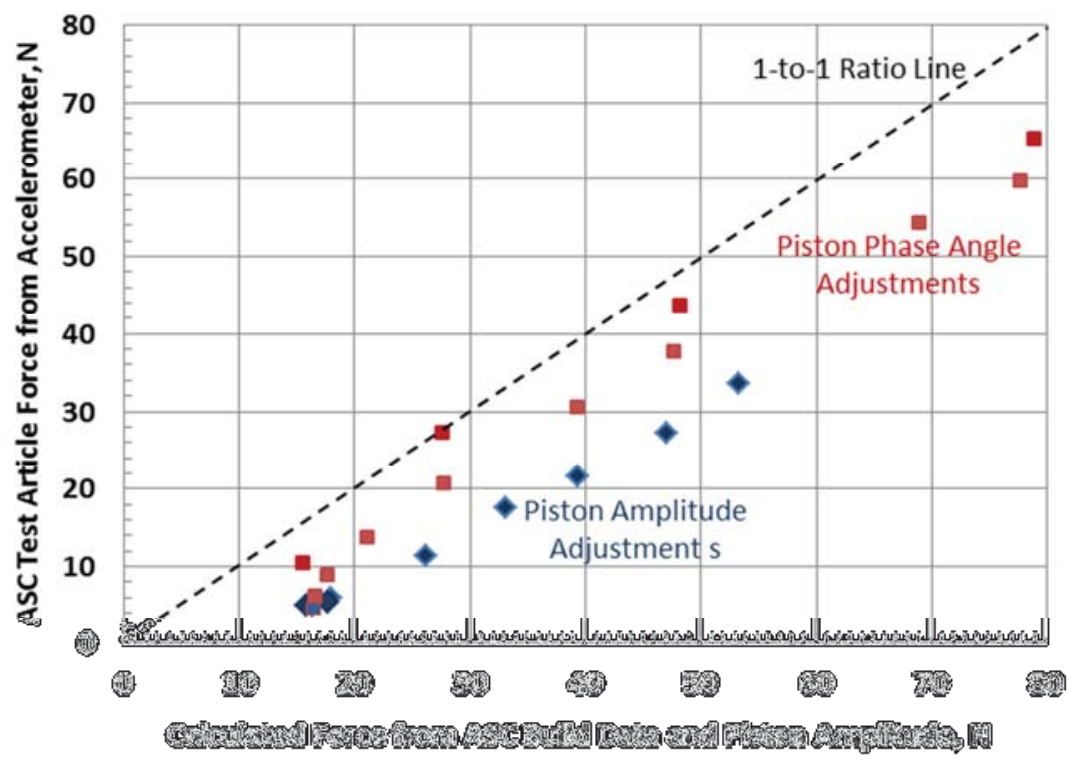

Figure 8. Comparison of Test Article Measured Force to Calculated Force from ASC Piston / Displacer Data.

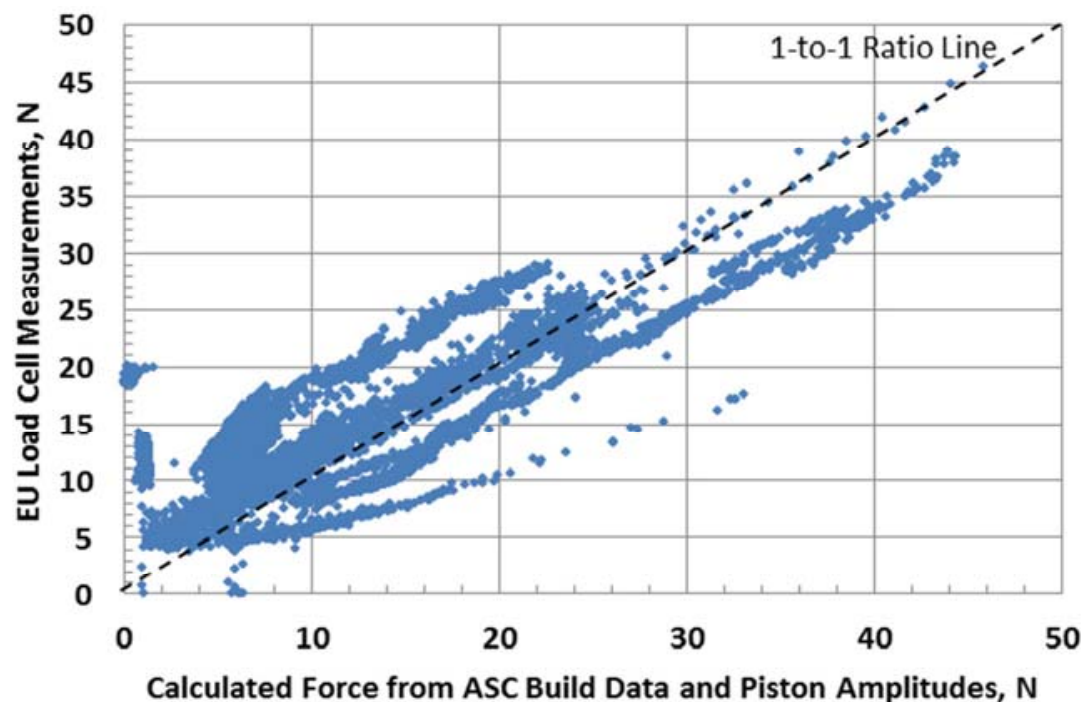

Figure 9. Comparison of EU ASRG Measured Force to Calculated Force from ASC Piston / Displacer Data. disturbance force produced can be incrementally mitigated by adjusting one or both ASCs if required. Changes made to piston amplitude will affect the operating hot-end temperature, however its effect on ASC power output is expected to be minimal.

\section{Fault Management}

The ACU is designed to be single-fault tolerant with an $\mathrm{N}+1$ redundancy. The failover of a faulted controller card to the standby card is accomplished via majority vote from the three cards or selfdetermine from various fault monitors on the cards. The fault monitors measure the states of the card circuitries and compare to input threshold values to determine if a fault occurred. The fault management requires that the total elapsed time from fault sensing, voting, controller card switch-over and transfer of ASC control be accomplished well within one operating ASC cycle, or $9.8 \mathrm{~ms}$, to prevent the piston from contacting hard stops. All fault handlings were tested with the EDU 4 OFA prior to the system-level test by injecting faults to the appropriate circuits while operating a pair of ASC interface simulators.

The control switchover from an active card to the spare card was demonstrated during the systemlevel test. With the ASCs operating at the steady-state condition and producing maximum output power, the AC power fault threshold was incrementally reduced until a fault signal was detected. This triggered a failover from card 1 to card 3 for the control of ASC-E3 \#1 as shown in Figure 10 for the voltage, current and piston sensor waveforms. Since the spare card does not have a piston sensor processing circuitry, the E3 \#1 piston signal is flat-lined after the failover. The failover duration was less than $600 \mu \mathrm{s}$ and the current and voltage waveforms, as shown in the figure, indicate no piston contact with the hard stops. 


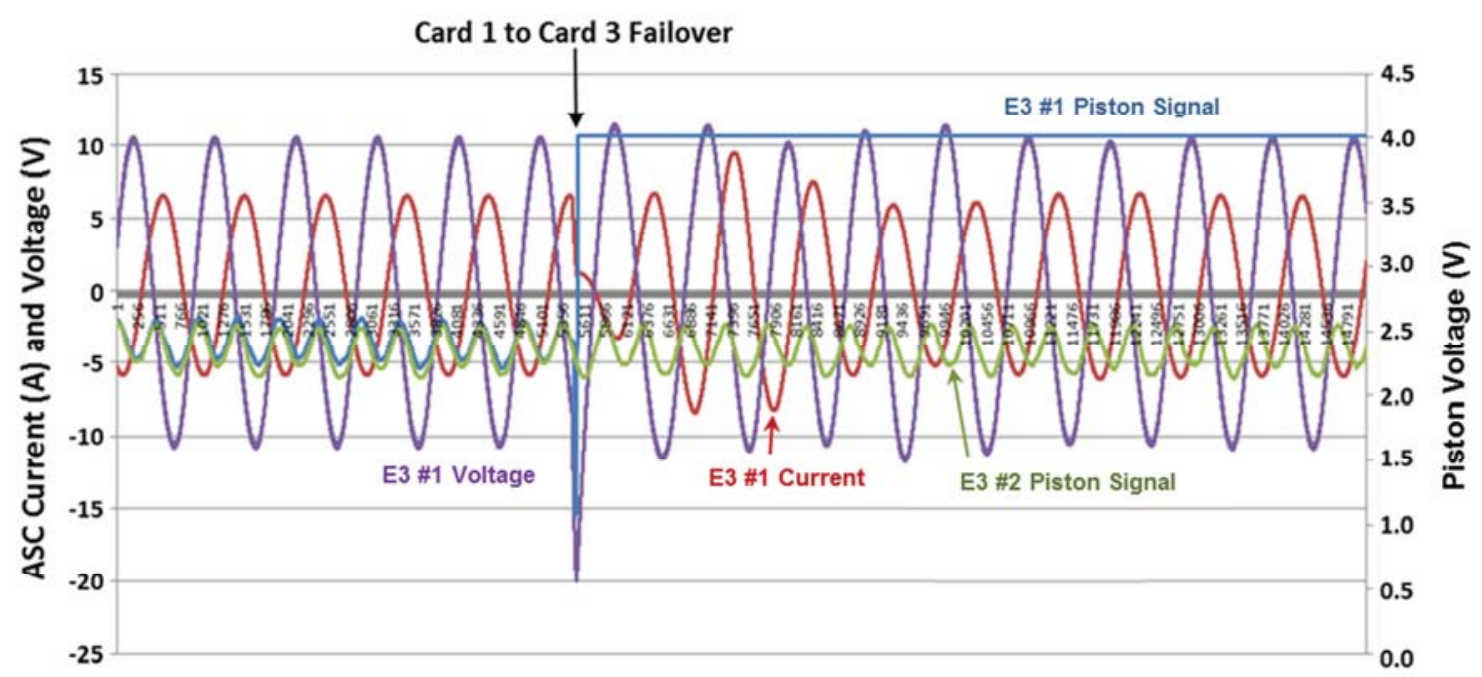

Figure 10. ASC-E3 \#1 Current / Voltage / Piston Sensor Waveforms during ACU Card Failover

\section{ASRG Scalability}

The highly efficient Stirling-cycle conversion technology and the associated control architecture are readily scalable to larger systems, when ease of host spacecraft packaging and integration is desired for high-power mission applications. Physical scaling of the ASRG to a design using four GPHS modules and higher-power ASC has been studied $^{3}$ outside the ASRG project. It was concluded that the basic ASRG GHA design configuration can be maintained with changes to the components to accommodate mass and envelope growth. Options for added features to improve additional waste heat rejection capability were proposed to achieve a nearly $300-\mathrm{W}$ system output and significant gain in specific power. Recent study also indicated that the ACU design and EEE parts selected for the ASRG are capable of flight operation to accommodate a $2 \mathrm{X}$ input power in its existing configuration. The limiting factor is the heat dissipation path for the H-bridge MOSFETs. Enhancement in controller card packaging should improve the overall ACU efficiency for this higher power application.

\section{Conclusion}

The completion of the ASRG flight design for future NASA mission applications culminated in the demonstration of the key flight-like ASCs and ACU to operate as an integrated unit representative of the flight ASRG operation. The test demonstrated the capability of the ASRG to provide steady DC power and external interfaces with the host spacecraft, including the system attributes in system startup, ASC control and operation, power rectification, DC output power management throughout nominal and out-of-range host voltage levels, ACU redundancy and fault management, and system command and telemetry via MIL-STD-1553 bus. This testing was highly successful, showing the viability of such a system for future deep space missions. These system-level operating characteristics will further be demonstrated in the extended operation currently under preparation at NASA GRC. The EDU 4 OFA is being packaged in a closed box at Lockheed Martin and the ASC-E3 \#1 and \#2 are being assembled in an engineering housing ${ }^{4}$ to support this test campaign.

\section{Acknowledgments}

This work is funded through the NASA Science Mission Directorate and managed by the Department of Energy. The authors wish to acknowledge the work of Michael Coe and Dave Busse of Lockheed Martin in the preparation and conduct of the test. The support to and participation in the test by the NASA Project and Sunpower teams are also appreciated.

\section{References}

${ }^{1}$ Chan, J., Dennis, H., Hoye, T., and Leland, D, "Development of Advanced Stirling Radioisotope Generator For Planetary Surface and Deep Space Missions", Proceedings of the $6^{\text {th }}$ International Energy Conversion Engineering Conference (IECEC), AIAA-2008-5768, Cleveland, OH, 2008. 
${ }^{2}$ Lewandowski, E.J., "Testing of the Advanced Stirling Radioisotope Generator Engineering Unit at NASA Glenn Research Center," Proceedings of the $10^{\text {th }}$ International Energy Conversion Engineering Conference and Exhibit (IECEC), AIAA-20124253, Atlanta, Georgia, 2012.

${ }^{3}$ Reyes, J., Britton, M., White, J.R., and Wood, J.G., "The Four-GPHS Stirling Generator: XP300," Proceedings of Nuclear and Emerging Technologies for Space (NETS-2011), Paper 3180, Albuquerque, New Mexico, 2011.

${ }^{4}$ Oriti, S.M., and Lewandowski, E.J., "Design of the Second Advanced Stirling Radioisotope Generator Engineering Unit," Proceedings of Nuclear and Emerging Technologies for Space (NETS-2014), American Nuclear Society, New Orleans, Louisiana, 2014. 